\title{
AS EXPERIÊNCIAS EM ASSESSORIA JURÍDICA UNIVERSITÁRIA POPULAR NO ESTADO DO PARÁ
}

\section{EXPERIENCES IN POPULAR ACADEMIC LEGAL ADVISORY IN THE STATE OF PARÁ}

\author{
Julyanne Cristine Barbosa de Macedo dos Santos \\ Universidade Federal do Pará - UFPA - (Belém, PA, Brasil) \\ Paula Regina Benassuly Arruda \\ Universidade Federal do Pará - UFPA - (Belém, PA, Brasil)
}

Recebimento: 8 abr. 2019

Aceitação: 16 jul. 2019

\begin{abstract}
Como citar este artigo / How to cite this article (informe a data atual de acesso / inform the current date of access):
SANTOS, Julyanne Cristine Barbosa de Macedo dos; ARRUDA, Paula Regina Benassuly. As experiências em Assessoria Jurídica Universitária Popular no estado do Pará. Revista da Faculdade de Direito UFPR, Curitiba, PR, Brasil, v. 65, n. 1, p. 9-38, jan./abr. 2020. ISSN 2236-7284. Disponível em: <https://revistas.ufpr.br/direito/article/view/65889>. Acesso em: 30 abr. 2020. DOI: http://dx.doi.org/10.5380/rfdufpr.v65i1.65889.
\end{abstract}

\section{RESUMO}

O presente artigo é derivado de pesquisa realizada para a construção de trabalho de conclusão de curso apresentado à Universidade Federal do Pará, que se baseou no levantamento sobre as experiências em Assessoria Jurídica Universitária Popular (AJUP) no estado do Pará. A pesquisa, de natureza qualitativa, foi orientada por uma revisão bibliográfica e uma pesquisa de campo realizada por meio de entrevistas semiestruturadas com 13 pessoas que tiveram experiência em AJUP e atuam profissionalmente em defesa de direitos humanos no Pará. Este trabalho tratará, inicialmente, dos elementos que formam a AJUP, seguindo para um resgate do histórico de núcleos que atuaram no estado do Pará e, por fim, apresentará alguns dos desafios identificados por meio dessa atuação. O surgimento das AJUPs no Brasil remonta à década de 1950, mas, apenas em 2004 houve as primeiras articulações no Pará, que resultaram na formação de quatro núcleos em períodos distintos. Apesar dos significativos avanços para a relação entre a universidade e a sociedade, os núcleos tiveram alguns limites de atuação, impostos pela dificuldade de renovação de membros e pela pouca expectativa concreta de continuidade de atuação profissional após a conclusão dos cursos de graduação. Como alternativas para enfrentamento desses obstáculos, refletiu-se sobre a necessidade de articulação entre as AJUPs em nível local e nacional, o cultivo permanente dos valores e princípios de AJUP e o direcionamento definido de suas atuações nas classes populares.

\section{PALAVRAS-CHAVE}

Assessoria Jurídica Universitária Popular. Direitos humanos. Educação popular.

\begin{abstract}
This article is derived from the research carried out as a procedure for the completion of course work, which was presented to the Federal University of Pará and was based on the survey on the experiences in popular academic legal advisory (AJUP, in Portuguese) in the state of Pará. The qualitative research was guided by a bibliographical review and a field research conducted through semi-structured
\end{abstract}


interviews with 13 people who had experience in AJUP and work professionally in defense of human rights in Pará. This work will initially address the elements that make up the AJUP, then will proceed to a historical review of nuclei that operated in the state of Pará and, finally, will present some of the challenges identified through this action. The emergence of AJUPs in Brazil dates to the 1950s, but only in 2004 the first articulations were made in Pará, which resulted in the formation of four nuclei in different periods. Despite significant advances in the relationship between the university and society, the nuclei had some limits of action, imposed by the difficulty of renewal of members and the little concrete expectation of continuity of professional performance after graduation. As alternatives to address these obstacles, it was reflected on the need for articulation between the AJUPs at local and national level, the permanent cultivation of the AJUP's values and principles and the definite direction of their actions with the popular classes.

\section{KEYWORDS}

Popular Academic Legal Advisory. Human rights. Popular education.

\section{INTRODUÇÃO}

Este trabalho busca apresentar reflexões sobre as experiências de atuação em Assessoria Jurídica Universitária Popular (AJUP) no estado do Pará, sendo derivado do levantamento realizado para construção de trabalho de conclusão de curso apresentado à Universidade Federal do Pará (UFPA). A pesquisa teve natureza qualitativa e foi orientada por uma revisão bibliográfica e uma pesquisa de campo realizada por meio de entrevistas semiestruturadas com 13 pessoas que tiveram experiência em AJUP e atuam profissionalmente em defesa de direitos humanos no Pará.

A proposta da AJUP surgiu a partir de articulações do movimento estudantil ainda na década de 1950, tendo sofrido um descenso durante a ditadura civil-militar iniciada na década seguinte e reemergido, posteriormente, no final da década de 1980, juntamente a diversos outros movimentos sociais e organizações populares. A AJUP propõe uma perspectiva de prática jurídica ao tratar de demandas coletivas que busca o fortalecimento da organização comunitária e enfatiza demandas com impacto social.

Para as entrevistas semiestruturadas (BRITTO JÚNIOR; FERES JÚNIOR, 2011), adotou-se um roteiro básico de perguntas e utilizou-se de um elemento, especificamente, do método de escuta política: tratar a vivência individual da(o) entrevistada(o) como consequência da experiência coletiva (GONDAR, 2004). Algumas entrevistas foram realizadas presencialmente, enquanto outras por meio de videochamadas.

As entrevistas foram estruturadas com o objetivo de investigar, de forma desencadeada, dentre outros, os seguintes pontos principais:

1) perceber como se deu a experiência de início e construção das respectivas AJUPs; 
2) reconhecer as dificuldades identificadas pelas(os) entrevistadas(os) na defesa de direitos humanos, seja na atuação como estudante em AJUP, seja posteriormente, como profissional;

3) identificar a influência da experiência em AJUP para a formação profissional e posterior continuidade na atuação em defesa de direitos humanos.

O alvo das entrevistas foram pessoas que participaram de algum dos quatro núcleos que atuam ou atuaram no Pará e continuam trabalhando em defesa de direitos humanos, a dizer: Núcleo de Assessoria Jurídica Universitária Popular “Aldeia Kayapó” (NAJUPAK) e Núcleo de Assessoria Jurídica Universitária Popular “Isa Cunha” (NAJUP Isa Cunha), de Belém; Núcleo de Assessoria Jurídica Universitária Popular “Cabano” (NAJUP Cabano) e Núcleo de Assessoria Jurídica Universitária Popular da Universidade Federal do Oeste do Pará (NAJUP - UFOPA) - este que, mais recentemente, incorporou a identidade de NAJUP Cabano, de Santarém-; e o Centro de Assessoria Jurídica Popular (CEAJUP), de Marabá. Não foi possível, porém, realizar entrevistas com membros do CEAJUP, apesar das tentativas de contato.

Este trabalho se desenvolve a partir da delimitação dos termos constituintes da AJUP, a dizer, “Assessoria”, “Jurídica”, “Universitária” e “Popular”, passando-se ao relato sobre as experiências de AJUP no Pará e partindo, finalmente, para uma análise sobre dificuldades e potencialidades da atuação da AJUP no estado.

\section{OS ELEMENTOS QUE CONSTITUEM A ASSESSORIA JURÍDICA UNIVERSITÁRIA POPULAR}

Aqui, discorrer-se-á sobre os elementos que formam a AJUP, a dizer: “Assessoria”, “Jurídica”, “Universitária” e “Popular”. O objetivo deste levantamento é traçar a perspectiva da AJUP sobre cada um dos seus elementos constituintes, e não os discutir de forma apartada e universal. Ademais, destacam-se alguns dos princípios que se correlacionam à construção em AJUP, a dizer: interdisciplinaridade; direito crítico; indissociabilidade entre ensino, pesquisa e extensão; diálogo entre universidade e sociedade; protagonismo estudantil; educação popular; busca da coletividade; horizontalidade; e emancipação e autonomia, a fim de forjar a base de entendimento dessa forma de atuação.

A “Assessoria” se coloca como uma contraposição à assistência judicial ao passo que busca romper com a perspectiva de acompanhamento processual de determinado caso individual específico, ainda que seja uma ação coletiva, a fim de “tutelar” e "resolver”, por meio das instituições jurídicas formais, as desavenças advindas das relações sociais. O ajuizamento de ações e o acesso ao sistema 
jurídico formal, por meio dos serviços legais tradicionais (CAMPILONGO, 1991), não é, porém, a única forma de acesso à justiça, pois existem diversos modos de produção do direito, não sendo este um monopólio de produção e distribuição do Poder Judiciário (WOLKMER, 2001).

Os serviços legais tradicionais são herança do positivismo jurídico em que se propunha uma autonomia total, desses serviços, em relação às influências sociais, buscando-se compreendê-lo como uma ciência pura. Essa postura de uso e produção do direito de forma a restringi-lo à técnica jurídica acaba por limitá-lo à aplicação da norma jurídica, afastando-o do fenômeno social a partir do qual é produzido e sobre o qual incide.

Nesse aspecto, o efetivo acesso à justiça, porém, exige que se faça a “politização” da prática jurídica e judicial (DUARTE, 2007) por meio do seu atrelamento à realidade, visto que o direito produz reflexos diretos na sociedade. Assim, a Assessoria vem no sentido de se contrapor ao cenário de reprodução e sustentação dos mecanismos de acesso à justiça tradicionais, caracterizando-se como um serviço legal inovador (CAMPILONGO, 1991), visto que se propõe a adentrar na discussão das causas das demandas encaminhadas ao tratamento pelo direito, atrelando-o à realidade a ele correlata, não apenas o utilizando para remediar lides específicas. A Assessoria, portanto, busca romper com o mecanicismo, individualismo e paternalismo da prática judiciária tradicional.

De forma a ilustrar os comparativos entre Assistência e Assessoria, torna-se válido comparar as diferenças entre os núcleos de prática jurídica (NPJ) e os Núcleos de Assessoria Jurídica Universitária Popular (NAJUP) que têm atuação no âmbito das universidades.

Durante a graduação, os Núcleos de Prática Jurídica são utilizados como um mecanismo de profissionalização dos estudantes de direito, ao disponibilizar atendimento jurídico, comumente às comunidades de baixa renda. Apesar da evidente importância desse mecanismo para a formação técnica e, ainda que precariamente, humanística do estudante, a prática nos NPJs se restringe ao favorecimento do acesso à justiça formal, individual, geralmente pelo ajuizamento de ações, não sendo capaz de envolver os estudantes a pensar as problemáticas sociais coletivas, comunitárias, existentes em seu entorno. Caracteriza-se, portanto, como mera e pontual assistência judiciária.

Por outro lado, como uma vertente de atuação em Assessoria Jurídica Popular (AJP), a AJUP busca ampliar o campo de formação dos estudantes de direito, pois está voltada para a prática de serviços legais inovadores, abrigando demandas coletivas centradas no protagonismo da participação comunitária e proporcionando o contato dos estudantes com a realidades sociais dos entornos (RIBAS, 2008). Como exemplos de atividades que podem ser desenvolvidas pelas AJUPs, conforme se delineará adiante quanto às experiências realizadas no Pará, estão, entre outras, o acompanhamento de atividades de regularização fundiária nas comunidades, elaboração de protocolos de consulta 
prévia e oficinas sobre educação popular em direitos humanos, tendo em vista que os diferentes núcleos podem atuar de formas muito variadas, incluindo ou não a possibilidade de ingresso e acompanhamento nas vias judiciais.

A maior diferença entre Assistência e Assessoria não reside especificamente nos mecanismos utilizados para atender às demandas, mas no alcance proposto pela Assessoria, que busca retomar a politização das demandas atendidas (CAMPILONGO, 1991, p. 56). A AJUP mescla ações para garantia de acesso à justiça a sujeitos coletivos organizados e atividades de educação popular em direitos humanos (SANTOS, 2011) na qual o objetivo não se restringe à resolução do conflito - seja judicial ou extrajudicialmente - (ESCRIVÃO FILHO; SOUSA JUNIOR, 2016), mas se propõe a ser um instrumento de transformação social, sendo necessário o contato real e efetivo com a comunidade ou coletivo no qual se atua a fim de perceber e captar sua linguagem própria (LUZ, 2007). Ainda que haja profissionais do direito que trabalhem com algumas comunidades, essa atuação não necessariamente parte desse viés de transformação social proposto pela AJUP e, conforme se demonstrará a seguir, pessoas que atuaram em núcleos durante a graduação e, hoje, permanecem trabalhando com Organizações não Governamentais (ONGs) e outras comunidades ou movimentos, percebem a relevância dessa vivência durante a universidade para a sua atuação profissional.

O elemento "Jurídico" da AJUP se sustenta em uma visão crítica do direito, pautada na análise da realidade jurídica por meio da teoria crítica, contrapondo-se à teoria clássica positivista, que se diz neutra, que observa o seu objeto à distância, desvencilhando a sua atuação do real, não alcançando a realidade sobre a qual incide. A teoria crítica do direito ou direito crítico não apenas contempla o seu objeto, não atua como mera observadora da realidade, ela não se coloca como uma figura estanque. Por meio da teoria crítica, é possível ter o entendimento da sociedade como uma totalidade; o direito não se coloca à parte da sociedade, mas dentro dela (RIBAS, 2008).

Ricardo Pazello (2014) concebe a AJUP como um uso tático do direito que permite a sua atuação em três frentes, sendo elas:

[...] a técnico-jurídica (pretexto que permite a discussão de problemas sociais e seu tensionamento via discussão jurídica), a político-organizativa (relacionada diretamente a uma teoria da organização política dos movimentos populares) e a pedagógico-popular (nível das metodologias que podem direcionar o trabalho dos assessores jurídicos como tais ou como incentivadores da organização popular) (PAZELLO, 2014, p. 459).

Assim, apesar de a perspectiva de Assessoria da AJUP se sustentar na interdisciplinaridade e buscar alternativas ao sistema judiciário, ela se mantém atrelada ao "Jurídico" associado a uma concepção crítica do direito que rompe com o pragmatismo e hermetismo do positivismo jurídico, buscando a reformulação paradigmática de sua atuação, bem como a sua (re)politização. 
Por esse viés, a atuação jurídica da AJUP ultrapassa os instrumentos tradicionais de atuação pelo direito, perpassando pela formação do estudante com base na teoria crítica do direito, pela interdisciplinaridade e pela consolidação desse trabalho mediante o fortalecimento das organizações populares.

As entidades de “assessoria jurídica popular” dividem-se em dois modelos: o campo da advocacia militante e o campo da assessoria universitária (LUZ, 2007). A assessoria jurídica popular é uma prática que envolve assessoria jurídica e atividades de educação popular. Desse modo:

\begin{abstract}
A assessoria jurídica popular, amplamente concebida, consiste no trabalho desenvolvido por advogados populares, estudantes, educadores, militantes dos direitos humanos em geral, entre outros, de assistência, orientação jurídica e/ou educação popular com movimentos sociais, com o objetivo de viabilizar um diálogo sobre os principais problemas enfrentados pelo povo para a realização de direitos fundamentais para uma vida com dignidade, seja por meio dos mecanismos oficiais, institucionais, jurídicos, seja por meios extrajurídicos, políticos e de conscientização (RIBAS, 2008, p. 46).
\end{abstract}

A assessoria jurídica universitária abrange as atividades de assessoria jurídica popular por meio de projetos ligados a universidades. Nesse grupo, enquadra-se a assessoria exercida por estudantes universitários que foi formulada em resposta à dificuldade de acesso da sociedade civil à justiça no Brasil.

A primeira experiência data da década de 1950, no Rio Grande do Sul, onde surgiu o Serviço de Assistência Judiciária Gratuita da Faculdade de Direito da UFRGS (SAJU-RS), vinculado à Universidade Federal do Rio Grande do Sul e que presta serviços de assessoria e assistência jurídica até hoje.

A prática de AJUP subentende a educação como ferramenta de construção da sociedade pautada em dois pilares principais: o da regulação e o da emancipação social, em que uma sociedade justa e igualitária seria pautada na harmonia entre os dois pilares (SANTOS, 2005). Acontece, porém, que o pilar da regulação, constituindo os elementos do Estado, do mercado e da comunidade, vivenciou historicamente um desequilíbrio devido à sobreposição do princípio do mercado em relação aos outros. Assim, houve a corrupção do papel transformador da educação, utilizando-a como um produto do mercado, constituindo o seu processo de mercantilização.

Santos já preconizava o tratamento da educação como mercadoria, em que a formação universitária é voltada para o mercado e se esvazia de criticidade: “a transformação da educação superior numa mercadoria educacional é um objetivo a longo prazo e esse horizonte é essencial para compreender a intensificação da transnacionalização desse mercado atualmente em curso" (SANTOS, 2011, p. 33). Sendo a produção do conhecimento uma formação histórica, nota-se que a 
educação, também, é baseada nas relações historicamente constituídas. Dessa forma, foi consolidada uma "hierarquia do conhecimento" (SANTOS, 2005), em que algumas formas de saber se sobrepõem a outras, sendo que os grupos sociais são constituídos com uma forma de conhecimento própria, submetendo, assim, a sociedade a essa hierarquia.

A “hierarquia de saberes”, por essa lógica, incute ao universitário uma posição hierárquica sobrelevada em relação aos demais estudantes ou cidadãos que não tiveram uma formação de "nível superior”. Dessa forma, há um grande distanciamento do conhecimento que é produzido no meio universitário, do conhecimento popular pelo qual são criadas diversas barreiras, físicas ou não, que segregam as comunidades de seu acesso.

O acesso ao ensino superior no Brasil, seja em universidades públicas ou particulares, passou de 4,94 milhões de matrículas registradas em 2006 para 8,05 milhões em 2016, segundo o Instituto Nacional de Estudos e Pesquisas Educacionais Anísio Teixeira (Inep), do Ministério da Educação (2016), sendo que, no mesmo ano de 2016, mais de um milhão e cem mil estudantes concluíram a educação superior. Ainda assim, esses números indicam que apenas $14 \%$ da população brasileira possui ensino superior completo, segundo o último relatório - que compara dados educacionais de 45 países - da Organização para Cooperação e Desenvolvimento Econômico (OCDE), publicado em setembro de 2017, o que demonstra uma extrema desigualdade no acesso a esse nível educacional, apesar dos avanços obtidos nas últimas décadas: essa realidade reflete diretamente as desigualdades sociais vivenciadas pelo povo.

Outro dado que demonstra as desigualdades camufladas pela progressão dos números é que 70,9\% das pessoas brancas com idade entre 18 e 24 anos estão no ensino superior, enquanto o número de pessoas negras, nas mesmas condições, é de apenas 46,8\%, segundo o último censo publicado pelo Instituto Brasileiro de Geografia e Estatística (IBGE), em 2016. É importante destacar, ainda, a grande discrepância quanto às regiões no país no que diz respeito à média de anos de estudos dos brasileiros: o Sudeste registra a maior média, com 8,6 anos, seguido pelo Centro-Oeste, 8,4 anos, e Sul, 8,2 anos; as regiões Norte e Nordeste apresentam um registro significativamente inferior a esse padrão de diferença, com 7,4 e 6,6 anos de estudo, respectivamente.

Esses dados demonstram a grande limitação de acesso à educação superior enfrentada por grande parte da população brasileira. Os perfis que ingressam nas universidades acabam por nutrir e manter a estrutura de segregação e distanciamento das formas de conhecimento produzidas dentro e fora dela.

Apesar da sua proposta emancipadora de construção do conhecimento, a universidade é, ainda, um espaço de reprodução das condições ideológicas dos grupos que, majoritariamente, a ela 
têm acesso. A propagação de valores como o individualismo e a competição, presentes no processo de acesso à universidade, são reproduzidos no decorrer da formação acadêmica dos estudantes que nela ingressam (ALMEIDA, 2015).

Essa realidade é resultado da metodologia de ensino bancária (FREIRE, 2013) incorporada à formação educacional que se reproduz no ensino superior e afeta, também, a formação de bacharéis em direito. Paulo Freire (2013) entende a educação como um processo dialético de construção do conhecimento, em que o “educar-se” se constitui a partir da relação contínua de troca de saberes entre os indivíduos, que se educam mutuamente, tendo como princípio a problematização e a inspiração à curiosidade e à compreensão do mundo.

A formação "bancária”, “mecanizada”, favorece a sustentação do legalismo "puro” nos cursos superiores, ao passo que dificulta a problematização do uso, construção e reprodução dos conhecimentos científicos. Nesse passo, a pesquisa e a extensão universitárias servem como uma alternativa para a (re)construção de outra forma de ensino nas universidades.

A tríade “ensino, pesquisa e extensão” é um dos pilares da Constituição de 1988, inserida no artigo 207, que dispõe que: “as universidades [...] obedecerão ao princípio da indissociabilidade entre ensino, pesquisa e extensão” (BRASIL, 1988), alocando-se a universidade a buscar o diálogo com a sociedade por meio da extensão, a fim de difundir os conhecimentos adquiridos e produzidos pela pesquisa e pelo ensino. Quanto a isso, é necessário que haja o questionamento da função social da universidade que se sustenta nos pilares de “ensino-pesquisa-extensão”, de forma a superar a extensão como um mero elemento dessa tríade que deve ser formalmente observado pelas políticas universitárias, mas, por outro lado, entendê-la como uma significativa ferramenta de transformação social (MONTEIRO; MARTINS, 2011, p. 257).

Assim, o elemento “universitário” proposto pela AJUP remonta à prática de uma extensão universitária popular, consciente da realidade na qual se insere, que seja capaz de resgatar a função social da universidade e colocar a produção do conhecimento a serviço do povo por meio de um projeto de “universidade popular” (DIEHL, 2009; PEREIRA, 2011), colocando o estudante como um sujeito ativo nas ações a serem realizadas e propondo uma prática educativa problematizadora, libertadora e autônoma, concebendo-a como um ato cognoscente e transformador.

Nesse passo, o protagonismo estudantil se forja como um dos princípios de atuação em AJUP em que o papel realizado pelos estudantes é relevante ao buscar contrapor o modelo de educação bancária presente no processo educativo mercantilizado, este visto como um "ato de depositar, ou de narrar, ou de transferir, ou de transmitir 'conhecimentos' e valores aos educandos, meros pacientes” 
(FREIRE, 2013, p. 94), pois o estudante é um sujeito ativo na propositura das ações a serem realizadas.

O elemento “popular” pode ser entendido como a “razão de ser” da prática em AJUP, pois é a sua diretriz fundamental de atuação. Indica a opção de utilização das ferramentas de assessoria para uma atuação próxima ao povo, aos movimentos sociais e populares, sendo esta uma característica fundamental da assessoria jurídica universitária popular (ALMEIDA, 2015). Dessa forma, buscamse estratégias de atuação próxima à classe trabalhadora de modo a intervir diretamente em sua realidade e propor o diálogo com os sujeitos com os quais se trabalha.

O “popular” também se refere à posição de fala escolhida: “ao lado do povo”, não sobre ele ou, muito menos, alheio à sua realidade. Por isso, a prática em AJUP fundamenta-se na metodologia de educação popular de Paulo Freire, pela qual se busca não falar “sobre o povo” ou “ao povo”, mas “com o povo” (FREIRE, 2011), mediante medidas e ações que objetivam a “conscientiz-ação” - ação na qual se vai tomando consciência ético-transformativa: libertação - e a prática da razão ético-crítica - crítica comunitária acerca da realidade histórica de opressão e responsabilidade do indivíduo pela valorização do outro (FREIRE, 2013).

A educação popular surge como uma tentativa de (re)pensar o sentido da própria educação. Nesse contexto, não mais existe uma forma ou metodologia de educar; pelo contrário, a educação popular traz em seu cerne a diferença, a resistência ao modelo formal e metódico da prática de educar (ALMEIDA, 2015).

Almeida (2015) destaca a preferência das AJUPs por grupos desorganizados da classe trabalhadora que se encontram ou se encontravam em elevados níveis de vulnerabilidade, com os quais se busca realizar um trabalho de fortalecimento dos sujeitos oprimidos, para a sua autonomia e emancipação. Orientada pelos princípios humanitários, pedagógicos e políticos de atuação nas comunidades e movimentos sociais na luta por direitos, a AJUP se propõe a ser um foco de resistência ante o tradicionalismo do sistema de justiça formal, ao fazer o resgate da politização da luta por direitos (ESCRIVÃO FILHO; SOUSA JUNIOR, 2016).

A educação popular, porém, não deve ser utilizada como mera metodologia, forjada por meio de leituras superficiais que floreiam o discurso e esvaziam a proposta na prática. A Assessoria Jurídica Universitária Popular se constrói a partir da necessidade de transformação da sociedade, pela construção conjunta entre os indivíduos, partindo, assim, para o tratamento coletivo de demandas de violações de direitos humanos pela ótica da própria vivência dos sujeitos coletivos que sofrem as violações, buscando romper com a sistemática tradicional de acesso à justiça por meio do sistema judiciário. Portanto, a AJUP, consolidada pelos elementos que a nomeiam, tem um local bem 
determinado por sua atuação: ao lado da luta popular, seja com movimentos sociais ou demais organismos populares, seja nas comunidades sem organização coletiva que podem ser auxiliadas por sua atuação.

Não é coerente reduzir esse pilar e a “politização” da atuação em AJUP a um viés partidário, por mais que não necessariamente o exclua. Incoerente, na verdade, seria se utilizar, mesmo que de forma velada, de discursos anti-partidários, suprapartidários ou suprapolíticos para desviar a assessoria de seu compromisso com a luta popular. Isso seria o mesmo que recair no discurso da neutralidade jurídica utilizando-se de uma ferramenta que nega veementemente essa proposição. É verdade que há diversos modelos de atuação em AJUP e diversas experiências diferenciadas vividas no Brasil (ALMEIDA, 2015). Não se incorpora, aqui, a prepotência de ditar o melhor ou pior modelo a ser seguido na atuação em AJUP, mas de fato a proposta central dessa forma de atuação se sustenta em pilares que não são passíveis de negociação.

A opção de classe, basilar da educação popular, implica um horizonte de transformação social que, se perdido, neutralizaria o potencial da AJUP de ser um agente de efetiva transformação em articulação com demais movimentos e grupos populares. Afastando-se do “popular” ou de outros de seus princípios, a AJUP perderia seu sentido, tornando-se outro mecanismo qualquer de acesso (ou não) à justiça.

Ademais, Almeida (2015), ao investigar a prática em AJUP, elenca alguns elementos que seriam os principais em sua constituição: a educação popular, a horizontalidade e o protagonismo estudantil, além da chamada “amorosidade”, que também pode ser referenciada como “tesão”, nas AJUPs, ou “mística”, nos movimentos sociais, desenvolvida pela e para a atuação dos movimentos populares em luta.

A “amorosidade” seria o desenvolvimento da identidade com a luta do povo, que carrega as diversas simbologias adotadas pelos movimentos populares na sua prática cotidiana, entre as quais se situa o Anel de Tucum:

O anel escuro, feito da madeira de uma planta nativa da Amazônia, representa para alguns setores das esquerdas o compromisso com as lutas sociais. Dizem que os escravos negros e índios usavam esse tipo de anel como aliança, simbolizando seus compromissos amorosos. Por isso, há quem localize as origens do anel nas lutas dos negros e dos índios contra a colonização a que eram submetidos (ALMEIDA, 2015, p. 307).

[...] sinal da aliança com a causa indígena, as causas populares. Quem carrega esse anel significa, normalmente, que assumiu essas causas e as suas consequências [...] Muitos, muitas, por essa causa, por esse compromisso, foram até a morte (O ANEL..., 1994, 43'21”). 
Esse símbolo de resistência histórica foi amplamente difundido pelos adeptos da teologia da libertação, corrente progressista da Igreja Católica que influenciou a formação de diversos movimentos populares, principalmente no campo, e do Partido dos Trabalhadores, na década de 1980, propagando os valores humanísticos da solidariedade e coletividade, tendo declarada a sua opção pelos pobres. A mística desenvolvida pelos movimentos populares carrega as simbologias da luta popular de forma a agregar seus militantes e, também, criar a identidade coletiva entre eles - de dentro para dentro e de dentro para fora -; a mística é criada como forma de (re)afirmar os valores da luta popular.

Difícil, porém, seria delimitar um conceito de mística, visto que ela é um elemento coletivo subjetivo, criado e entendido na prática da atuação dos movimentos. Aqui, arrisca-se à proposta de entendê-la em dois sentidos: a "mística" como o sentimento de pertencer à luta e o seu reconhecimento nela, esse "sentir” como algo "místico”; e a "mística” como ferramenta, metodologia de sensibilização e criação de identidade.

A primeira vertente é constituída pelo reconhecimento de identidade com o povo e o compromisso na atuação pelas causas populares, enquanto a segunda representa os mecanismos de sensibilização: utilizam-se de poemas, teatro, músicas e demais práticas, espontâneas ou minimamente planejadas, para a criação, fortalecimento e reafirmação da identidade com as lutas populares. A mística como ferramenta, porém, não é uma metodologia definida de trabalho, mas uma formulação coletiva daqueles que a utilizam como instrumento de fortalecimento da resistência na luta.

O “tesão” é a incorporação da mística pelas AJUPs, que pode ser entendido como o “princípio da paixão/prazer” (SAMPAIO OLIVEIRA, 2003, p. 62), o “apaixonamento” (ALMEIDA, 2015) desenvolvido pelas suas práticas. Como retrato, a Rede Nacional de Assessoria Jurídica Universitária ${ }^{1}$ (RENAJU) construiu um documento denominado “Estatuto do Tesão” (RENAJU, 2016), comumente lido nos encontros promovidos pela Rede, no qual são reafirmados valores emancipatórios da prática em AJUP e se define o tesão como “a paixão, o entusiasmo, a alegria, a motivação e a juventude necessárias à construção de um mundo livre e igualitário, onde a felicidade e a beleza sejam experiências cotidianas” (REDE NACIONAL DE ASSESSORIA JURÍDICA POPULAR, 2016). Apesar da possibilidade de assumir um caráter despolitizante (ALMEIDA, 2015, p. 311), pela aparente necessidade de produzir “consensos” para os quais esse elemento seria um

1 Rede nacional formada pelas AJUPs que atuam em diversas pautas e diferentes estados do Brasil. Será mais bem tratada a seguir. 
caminho, a mística é capaz de somar na construção de movimentos populares quando associada ao objetivo de criação de identidade.

A “mística, “amorosidade” ou "tesão”, quinto elemento estruturante da prática em AJ(U)P, nada mais é, por fim, do que a demonstração do envolvimento dos profissionais e estudantes que reconhecem seu compromisso com a luta popular e atuam em observância aos pilares aqui discorridos, vinculando sua atuação ao caráter emancipatório da Assessoria Jurídica Universitária Popular.

\section{ENTRE PAR(ÊNTES)ES: BREVE HISTÓRICO DAS ASSESSORIAS JURÍDICAS UNIVERSITÁRIAS POPULARES NO ESTADO DO PARÁ}

Neste momento, busca-se realizar o resgate de atuação das AJUPs no Pará. Como o histórico de alguns núcleos não foram documentados de forma concisa, este trabalho buscou reunir diversos relatos sobre as experiências de AJUPs no estado por meio de entrevistas semiestruturadas que foram realizadas com pessoas que atuaram ou atuam nesses grupos. Para isso, os roteiros de entrevistas variaram de acordo, principalmente, com o núcleo no qual a pessoa atuou e a época da atuação, mas tiveram como foco o resgate do histórico de experiências das AJUPs. Algumas perguntas foram comuns a todas as entrevistas, como a questão sobre as principais dificuldades enfrentadas durante os períodos de atuação, quais atividades foram desenvolvidas e como a atuação em AJUP contribuiu para influenciar a escolha pelo atual caminho profissional que a pessoa entrevistada passou a seguir. De posse dessas informações coletadas nas entrevistas e mediante pesquisa bibliográfica, organizouse o histórico que se apresenta neste tópico.

A década de 1950 foi marcada pela expansão das universidades no Brasil, sendo seguida pelo fortalecimento de novas correntes políticas e do movimento estudantil - com destaque para a influência do surgimento da União Nacional dos Estudantes (UNE) no ano de 1937 -, traduzido na resistência protagonizada por estudantes ao regime da ditadura civil-militar (ALMEIDA, 2015; MONTEIRO; MARTINS, 2011).

As AJUPs surgem, nesse contexto, associadas à experiência de assistência judiciária promovida pelos núcleos de prática jurídica, também chamados de escritórios modelo, a partir do questionamento sobre esse modelo de extensão universitária, favorecidas pelos debates sobre a reforma universitária promovidos por estudantes da UNE, que passou a promover espaços como os centros populares de cultura e a UNE Volante, com atividades que envolviam intervenções culturais e agitação política e se propunham a ultrapassar os limites das universidades e estabelecer diálogos 
diretos com a sociedade a partir de um projeto político de emancipação da classe trabalhadora (ALMEIDA, 2015).

As primeiras experiências de AJUP foram registradas na Universidade Federal do Rio Grande do Sul e na Universidade Federal da Bahia, pela criação dos Serviços de Assessoria Jurídica Universitária (SAJUs), conhecidos como SAJU-UFRGS e SAJU-BAHIA, respectivamente, a fim de buscar uma aproximação dos debates mais reais do direito e em contrapartida à "prática forense” ofertada pelas universidades, que tinha caráter meramente teórico.

Durante a década de 1970 e até meados da de 1980, porém, as atividades de AJUP foram atrofiadas pelo regime político vigente (RIBAS, 2008), voltando a ter destaque entre as décadas de 1980 e 1990, quando o período político de redemocratização foi delineado pelo surgimento e fortalecimento de diversos movimentos sociais, muitos ainda fortemente atuantes na sociedade, como o Movimento dos Trabalhadores Rurais sem Terra (MST), diante dos quais a perspectiva de AJUP se fortaleceu, tendo como base, também, a organização dos estudantes em suas executivas de curso:

\section{A intervenção conjunta de estudantes e MS's [sic] foi considerada por muitos grupos como fundamental para a construção de um paradigma de extensão ligado aos interesses de uma transformação profunda e radical na sociedade para a efetivação dos Direitos Humanos (MONTEIRO; MARTINS, 2011, p. 259).}

Em 1995 foi fundada a Rede Nacional de Advogados e Advogadas Populares (RENAP), atuante em todo o território nacional e, sob sua influência, no ano de 1996, foi criada a Rede Nacional de Assessoria Jurídica Universitária (RENAJU), com a função de propagar a prática em AJUP nas universidades e promover encontros presenciais para a construção da rede de partilha de experiências de atuação (MONTEIRO; MARTINS, 2011), como os Encontros Nacionais (ERENAJUs), os Encontros Regionais (ERAJUs), os Encontros de Assessoria Jurídica (ENAJU) inseridos nos Encontros Nacionais dos Estudantes de Direito (ENEDs) (PEREIRA; OLIVEIRA, 2009, p. 154) e, posteriormente, os Cursos de Formação Política (CFPs), de caráter nacional e que tiveram sua primeira edição em 2012.

O ano de 2004 marca o despertar da articulação de AJUPs no estado do Pará. Durante o ENAJU ocorrido na Universidade Federal do Pará (UFPA), campus Belém, os estudantes locais tiveram contato com a prática de AJUP. A partir de então, surgiram dois grupos na cidade: o Núcleo de Assessoria Jurídica Universitária Popular Aldeia Kayapó (NAJUPAK) e o Núcleo de Assessoria Jurídica Universitária Popular Isa Cunha (NAJUP Isa Cunha). Posteriormente, foi articulado o NAJUP Cabano, em Santarém, e o Centro de Assessoria Jurídica Popular (CEAJUP), em Marabá. 
Nessa época, o curso de direito do campus Belém da UFPA contava com apenas esses dois projetos de extensão, mostrando seu caráter pioneiro na extensão jurídica (MONTEIRO; MARTINS, 2011).

O NAJUP Isa Cunha se articulou a partir das demandas da comunidade do bairro de Terra Firme, em Belém, tendo como apoio a contribuição de líderes comunitários do bairro, pelo trabalho na Rádio comunitária “Cidadania FM”, utilizada como meio de comunicação popular para realizar a formação em direito com a comunidade entre os anos de 2005 e 2006. O processo de criminalização sofrido pelo grupo e a dificuldade de regularização das rádios comunitárias dificultou a continuidade de sua atuação, o que, por outro lado, motivou a contribuição na formação do Fórum de Rádios Comunitárias, em 2007, como resposta à criminalização que ocorria em toda a região metropolitana de Belém. Por ação do Governo do Estado, porém, sua atuação foi paralisada.

Posteriormente à experiência com as rádios comunitárias no bairro de Terra Firme, o Núcleo passou a pautar a questão da saúde na região metropolitana de Belém de 2009 a 2010 - demanda fortalecida pelo processo de privatização de equipamentos de saúde municipais e estaduais. Em parceria com estudantes universitários, do Instituto de Ciências da Saúde da UFPA e sindicalizados no SINSAÚDE municipal, o NAJUP contribuiu na proposta de criação de um fórum popular de saúde do Pará, passando-se a

estudar o SUS no Pará, acompanhar a organização do Fórum Popular de Saúde e preparar-se para promover ações de educação popular com os trabalhadores, seja no tocante a promoção da saúde no Brasil de forma interdisciplinar, seja no que diz respeito a saúde do trabalhador (MONTEIRO; MARTINS, 2011, p. 261).

Após essa experiência, o núcleo iniciou uma atuação em parceria com o MST no assentamento Mártires de Abril, localizado na Ilha de Mosqueiro, Pará, a partir do mapeamento e realização de oficinas sobre o resgate histórico do assentamento e direito previdenciário.

Paralelamente a esses projetos, o NAJUP desenvolveu, desde 2007, o projeto "Cineclube Isa Cunha - arte e(m) debate”, pelo qual inseria o debate sobre formação em direitos humanos na universidade, a fim de discutir temáticas relacionadas à luta popular.

O NAJUPAK, por outro lado, pautou seu trabalho em três frentes principais: pelo projeto “Juventude Cidadã: Conquistando Direitos e Sensibilizando Deveres”, o "Rodas de Diálogos” e o “ANEM”, entre 2004 e 2011 (SANTOS; CAVALCANTE, 2014).

O projeto Juventude Cidadã teve diversas versões ao longo dos anos. O trabalho era realizado com estudantes de escolas públicas do município de Belém, com o objetivo de instigar a articulação e mobilização dos estudantes ante seus direitos e deveres, fazendo com que eles se reconhecessem como sujeitos de direitos e agentes de transformação social nas suas escolas e comunidades 
(BERNARDO; SANTOS; SANTOS, 2014). De 2007 a 2009, o núcleo promoveu a realização de oficinas com a temática de direitos humanos e cidadania, que eram realizadas com crianças do $6^{\circ}$ ao 9ªnos da escola José Alves Maia, do bairro do Guamá, em Belém. Em 2010 e 2011, desenvolveu as mesmas atividades com estudantes da Escola Municipal Prof. Francisco Nunes.

Em 2013, o NAJUPAK sofreu algumas alterações no seu campo de atuação, passando a atuar com jovens a partir de 15 anos de quatro escolas públicas do bairro de Jurunas, em Belém, tendo aprofundado seu trabalho, em 2014, com a EEEFMS Camilo Salgado, também no bairro de Jurunas.

Por outra frente, o núcleo desenvolveu o projeto "Rodas de Diálogos”, em que debatia, na universidade, temas de relevância social, tendo como público os discentes da UFPA e de outras instituições, pautando sempre a interdisciplinaridade e, portanto, atraindo alunos dos mais diversos cursos da área de ciências humanas e ciências sociais aplicadas.

A outra frente de atuação do núcleo foi o projeto ANEM - A Arte e a Não Exatidão da Matéria -, que visava promover o debate sobre temas relacionados aos direitos humanos, sociedade e literatura entre os integrantes do projeto e que foi executado entre os anos de 2010 e 2011.

Em 2014, o NAJUPAK comemorou 10 anos de existência, marcado pelo Seminário "Do Sonho ao Acontecer: 10 anos de NAJUPAK”, realizado nos dias 25 e 26 de setembro de 2014, no Instituto de Ciências Jurídicas da UFPA, no qual foi lançada uma publicação digital com a compilação de diversos artigos de estudantes e profissionais que atuam e discutem a assessoria jurídica popular no Brasil.

A decisão pela formação de dois núcleos diferentes, no mesmo contexto e segundo relatado em algumas entrevistas, deu-se por dois fatores principais: a escolha da temática de atuação e a diferença na própria articulação dos núcleos: o NAJUP Isa Cunha iniciou a prática extensionista desde o ano seguinte à primeira articulação dos estudantes, tendo o aspecto de aproximação aos movimentos sociais como traço marcante de sua atuação. O NAJUPAK, por outro lado, empregou cerca dos dois anos iniciais para o estudo e formulação sobre temas relacionados à AJUP e não apresentou uma tendência inicial à articulação com movimentos sociais, havendo uma mudança de postura apenas por volta de 2013, quando, inclusive, participou do Estágio Interdisciplinar de Vivência (EIV)² em 2014, contribuindo na sua organização no ano seguinte, sendo que o NAJUP Isa Cunha já estava em contato com essa experiência desde a primeira edição em 2009.

2 O Estágio Interdisciplinar de Vivência (EIV) é uma proposta organizada por estudantes e movimentos sociais a fim de aproximar seus participantes da realidade dos movimentos que atuam na localidade onde é realizado, buscando estabelecer um processo educativo a partir de vivências, em grande parte em áreas rurais e discussões sobre o papel da universidade. 
Em 2009, o NAJUPAK e o NAJUP Isa Cunha sediaram o I Encontro Paraense de Assessoria Jurídica Universitária Popular (EPAJUP), a fim de aproximar os núcleos que atuavam nas diversas regiões do estado, incluindo-se o Centro de Assessoria Jurídica Popular, de Marabá e o NAJUP Cabano, de Santarém, além de uma articulação inicial de um grupo de “Assessoria Intercultural e Interdisciplinar em Direitos Humanos (AIDH)” que estava sendo organizado em Altamira (MATOS, 2014), com a proposta de possibilitar, pela primeira vez na história da AJUP, a constituição da entidade fora do curso de direito (OLIVEIRA; RAMOS 2012), mas, posteriormente, não continuou as atividades. A partir daí, foi criada a Rede de Assessoria Popular Emancipatória (REAPE/PA) ${ }^{3}$.

O CEAJUP foi articulado paralelamente às discussões sobre um novo projeto pedagógico do curso de direito do campus de Marabá, a partir da necessidade de o curso assumir uma função social emancipatória, atuando, hoje, por meio dos projetos de extensão “Advocacia Popular em Acampamentos de Sem-Terra” e "Direito de Morar", pelos quais atuou, inicialmente, nos acampamentos Dina Teixeira e Zumbi dos Palmares, e, mais recentemente, nos acampamentos Helenira Resende e Dalcídio Jurandir, ambos localizados às margens da Rodovia PA150, o primeiro no município de Marabá e o segundo no município de Eldorado dos Carajás (BARROS; SOUZA, 2010), além do projeto “Atendimento a mulheres vítimas de violência doméstica”, pelo qual atende um público de famílias em ocupações urbanas de Marabá (RIBEIRO, 2016).

O NAJUP Cabano foi resultado de uma articulação pré-existente de estudantes, predominantemente, do curso de direito da UFPA ${ }^{4}$ local. O curso sofria os clássicos problemas dos campi do interior do estado, como falta de estrutura e de professores e atividades que envolvessem os alunos em discussões políticas importantes. Por essa razão, grupos de estudantes organizados no movimento estudantil local passaram a articular algumas atividades, com a proposta de discutir o direito a partir da realidade da região e suprir algumas lacunas da Universidade no município.

A organização do Festival de Direitos (FD), a partir de 2008, foi o carro-chefe de articulação desses estudantes, levando à proposta de discutir o "Direito Achado na Beira do Rio"5, que se propunha à aproximação entre o ensino do direito e as vivências e demandas locais.

O primeiro contato com a ideia de AJUP se deu pela participação de um dos integrantes fundadores do núcleo em um ENAJU ocorrido em Belém no ano de 2009. Posteriormente, os estudantes iniciaram os estudos sobre o tema, com destaque para a realização do I Seminário do

\footnotetext{
3 https://bit.ly/36pcb0p.

4 No período de formação do núcleo, a universidade local foi a Universidade Federal do Pará. No ano de 2013, foi criada a Universidade Federal do Oeste do Pará.

5 Tema empregado às edições dos Festivais de Direitos com a proposta de pensar perspectivas locais de formação e atuação em direito.
} 
Núcleo de Assessoria Jurídica Universitária Popular, ocorrido em Alter do Chão em agosto de 2010, que buscou promover uma formação mais densa sobre a atuação em AJUP.

Como os estudantes que eram envolvidos com a realização dos festivais de direitos das edições anteriores foram os articuladores do NAJUP, entre 2008 e 2016, ano da última edição do festival até o momento, o já constituído NAJUP Cabano esteve oficialmente à frente dessa construção a partir de sua consolidação, adotando, assim, a atividade como própria do núcleo. Além disso, a partir de 2014, o núcleo passou a organizar um evento denominado “Diálogos Insurgentes”, prévios aos festivais de direitos, a fim de introduzir as temáticas de discussão dos festivais dos respectivos anos por meio de exibição de filmes e documentários e pela realização de debates entre os próprios integrantes do núcleo e o público em geral interessado nos temas.

No período inicial de articulação do núcleo, porém, discutia-se a extinção da Universidade Federal do Pará na região e a simultânea criação da Universidade Federal do Sudoeste do Estado do Pará (UFOPA). Nesse contexto, os estudantes estavam articulados para além da atuação no NAJUP, enfrentando os embates decorrentes da criação da nova universidade, que trazia a proposta de um modelo de desenvolvimento, apresentado pelo Ministério da Educação (MEC), que não estava bem definido e dava margem à utilização da universidade para a execução de grandes projetos de exploração natural predatória.

Esse contexto, também, influenciou os estudantes a decidirem não estabelecer um vínculo formal com a Universidade, pela discordância do modelo de universidade que estava sendo implantado e pelo receio de ter sua atuação vinculada à instituição, carecendo-lhe de autonomia. Ainda assim, formularam um projeto político que estabelecia suas diretrizes e objetivos de atuação.

A conjuntura local e o próprio perfil de estudantes voltados à atuação no movimento estudantil na época, além do raro contato com outras AJUPs, movimentos sociais e demais sujeitos, além de participações pontuais nos eventos e somados à inexperiência na prática de AJUP para o início das atividades de extensão, fez com que o núcleo tenha executado eventos apenas na Universidade $^{6}$, o que não diminui, porém, a importância dessa articulação na região, visto que o Festival de Direitos, construído pelo protagonismo estudantil desses estudantes, foi de extrema relevância para a Universidade, que, inclusive, passou a incorporá-lo à programação oficial da instituição, constituindo-se como um importante espaço de debate e articulação dos estudantes sobre um novo modelo de educação universitária.

6 Há o registro de apenas um evento realizado fora da UFPA, o “Tribunal Popular da Bacia do Tapajós”, realizado durante o "V Fórum Social Pan-Amazônico”, organizado em conjunto com a Frente de Defesa da Amazônia (FDA). 
O Direito Achado na Beira do Rio, pelo ano de 2009, regou sementes e deu frutos: como a mais recente articulação de AJUPs no estado, alguns estudantes que participaram da organização do Festival de Direitos nos últimos anos se propuseram a organizar uma nova AJUP, com outros moldes, diferenciando-se da experiência anterior por um fator fundamental: a vinculação à universidade anterior à atuação do núcleo.

Apesar de, inicialmente, ser denominado de NAJUP-UFOPA, passou, posteriormente a adotar a identidade de NAJUP Cabano. Atualmente, a nova constituição do núcleo foi consolidada a partir da formulação e aprovação de um programa de extensão vinculado à UFOPA, com atuação a partir de quatro eixos principais: direito e consulta prévia; ocupações urbanas; formação jurídicopolítica e educação popular em direitos humanos.

Em razão da complexidade que seria realizar no presente trabalho o relato sobre todas as atividades já desenvolvidas pelo núcleo, atém-se aqui a destacar que os focos de atuação do NAJUP UFOPA tiveram duas influência principais: a vivência anterior de alguns dos estudantes fundadores do núcleo com a temática relacionada a povos e comunidades tradicionais, sendo que o eixo de educação popular em direitos humanos conta com o protagonismo de um estudante indígena do curso de direito da instituição; e a de uma das coordenadoras que trabalha com a questão de ocupações urbanas.

O primeiro momento de apresentação do grupo como NAJUP foi durante a audiência pública sobre o Plano Diretor da cidade de Santarém, ocorrida em novembro de 2017, já havendo uma programação de formações e novas atividades para os meses subsequentes.

Atualmente, apenas o NAJUP-UFOPA e o CEAJUP permanecem atuantes no estado do Pará, mas as experiências de atuação das mais diversas formas demonstram a possibilidade de fortalecimento dessa ferramenta no estado.

Faz-se evidente a variedade de perspectivas e focos de atuação dos diversos núcleos que atuaram ou atuam no Pará, sendo relevante refletir sobre as dificuldades enfrentadas pelos grupos para sua articulação e atuação, a fim de construir mecanismos de fortalecimento dessas atuações. Sendo assim, o tópico seguinte irá analisar as dificuldades comuns encontradas pelas entrevistadas e entrevistados durante sua atuação em AJUP no Pará e propor algumas estratégias de superação de obstáculos, (re)articulação e fortificação das AJUPs no estado. 


\section{COM COMEÇO, MEIO E... O PERMANENTE CAMINHAR NO HORIZONTE DA UTOPIA $^{7}$ : OS DESAFIOS DA ASSESSORIA JURÍDICA UNIVERSITÁRIA POPULAR EM DEFESA DE DIREITOS HUMANOS NO ESTADO DO PARÁ}

Este tópico tem como base, principalmente, as entrevistas semiestruturadas realizadas com pessoas que vivenciaram a experiência de AJUP no Pará e o estudo realizado por Ana Lia Almeida (2015) sobre a atuação das AJUPs no Brasil, utilizado para direcionar a análise das entrevistas. A autora compreende o apoio às lutas dos movimentos sociais como o principal elemento caracterizador da Assessoria Jurídica Popular, influenciado pelo momento econômico e político do país, que foi caracterizado por uma grave crise a partir dos anos de 1970.

A decisão da RENAJU, em 2006, por apoiar explicitamente de forma crítica “os movimentos sociais que lutam contra as formas de opressão” (RENAJU, 2006 apud ALMEIDA, 2015, p. 94), denota a realidade dessa aproximação das AJUPs, havendo um destaque para as AJUPs atuantes no Norte e Nordeste (ALMEIDA, 2014). A indignação com a injustiça social, com a exploração e com a miséria, e a decisão por trabalhar em prol do "povo pobre” colocam a prática de AJUP ao lado de diversos grupos protagonistas de lutas sociais.

Vale ressaltar, novamente, que as realidades das diversas regiões do estado são significativamente diferentes, bem como as lutas travadas em cada uma delas e as demandas de atuação de cada região, o que provocou a variedade dos diversos núcleos do estado, que trabalharam com a pauta desde conflitos agrários, direitos de povos e comunidades tradicionais, até a defesa de direitos de crianças e adolescentes. Apesar da diversidade de sujeitos, realidades e focos de atuação que constituíram as AJUPs no estado, foi possível identificar, por meio das entrevistas, alguns traços comuns na constituição delas.

O primeiro a ser destacado é quanto à própria criação de identidade com a atuação em AJUP e à predominância do protagonismo estudantil na articulação dos núcleos. Os estudantes, após terem contato com a experiência de $\mathrm{AJUPs}^{8}$, passaram a se articular para a construção de uma organização semelhante.

Todos os entrevistados que participaram do início da construção dos núcleos identificaram o processo coletivo de entendimento sobre o trabalho em AJUP como o propulsor do "descobrir-se coletivamente” (OLIVEIRA, 2010, p. 114), que se deu, comumente, por meio dos estudos e discussões sobre temas centrais da AJUP, como educação popular e direito crítico, havendo, em

\footnotetext{
Em alusão ao poema “Para que serve a Utopia? ”, de Eduardo Galeano.

8 Como relatado no tópico 1, no Pará as AJUPs foram formadas, em geral, após encontros de estudantes, como o ENAJU, em 2004, que influenciou a criação do NAJUPAK e do NAJUP Isa Cunha, e o ENAJU 2009, que influenciou a criação do NAJUP Cabano.
} 
alguns relatos, o destaque para o contato com professores que se disponibilizavam a contribuir burocraticamente com as atividades como um fator de fortalecimento desse vínculo entre as/os estudantes. Esse processo passa pelo desencanto com a formação jurídica hegemônica por meio de um “despertar ideológico” (ALMEIDA, 2015, p. 126) para a luta dos trabalhadores e demais sujeitos vulnerabilizados.

Ao serem perguntados sobre o processo de articulação inicial dos núcleos e, posteriormente, de pretensão, quando ainda estudantes, de atuar profissionalmente em defesa de direitos humanos, foi possível notar, tanto pela fala como pela expressão das(os) entrevistadas(os), o elemento da “amorosidade” pelo atuar em AJUP e o sentimento de pertencer ao grupo e à causa que decidiram defender.

O segundo traço comum percebido foi quanto às discussões sobre a inserção da ideia de AJUP nas universidades. O vínculo institucional como projeto ou programa de extensão foi destacado como uma estratégia importante para a atuação e fortalecimento da AJUP, seja pela possibilidade de apoio financeiro, seja pela credibilidade da qual o núcleo era dotado quando vinculado à universidade.

Ainda assim, há o receio de que a vinculação possa engessar o trabalho da AJUP, especialmente em momentos de conflitos políticos acalorados, a exemplo do NAJUP Cabano, que enfrentou a extinção do campus da UFPA local e a simultânea criação da UFOPA, período em que se discutiu o modelo de desenvolvimento que estava sendo pautado pelo MEC ao constituir a nova Universidade. Nesse contexto, os estudantes articulados no NAJUP decidiram por não vincular o núcleo à Universidade, em razão das discordâncias políticas.

Essa questão também foi investigada por Almeida, que identificou essa postura como uma “crise de identidade” (ALMEIDA, 2015, p. 321) em que a AJUP, por vezes, aloca-se entre os movimentos estudantis tradicionais e a prática extensionista: nasce do movimento estudantil, mas se aproxima da identidade de extensão ao buscar se afastar dos vícios do ME, ainda que se proponham expressamente a uma “disputa política” (ALMEIDA, 2015, p. 326), por meio da extensão.

Por outro lado, é um equívoco entender a vinculação das AJUPs às universidades como um fator determinante à sua atuação. Ainda durante as entrevistas, investigaram-se as possíveis influências das relações existentes entre gestões de centro acadêmicos, faculdades, institutos e administrações superiores, sendo possível identificar o elemento da autonomia das AJUPs como predominante. De fato, as AJUPs que atuaram em meio a gestões mais abertas e que entendiam o perfil e importância dos núcleos tiveram a possibilidade de maior abertura tanto para diálogo com professores, como acesso a editais para obtenção de recursos e convites para a participação em eventos destinados ao diálogo com demais estudantes, como semanas dos calouros e afins. 
Nesse contexto, porém, havia a dificuldade de se adaptar aos parâmetros burocráticos de vinculação estabelecidos pelas universidades para a formalização de algum vínculo. Algumas(ns) entrevistadas(os) relataram primeiro a dificuldade de encontrar um professor disposto a entender o projeto e contribuir com ele.

A divulgação das atividades das AJUPs era e é feita, geralmente, por listas de e-mails, divulgação em redes sociais e em salas de aula, a fim de aproximar estudantes, bem como pela realização de eventos e projetos próprios, a fim de atrair novos estudantes, como no caso das "Rodas de Diálogos", promovidas pelo NAJUPAK, e do "Cineclube Isa Cunha - arte e(m) debate”, promovido pelo NAJUP Isa Cunha.

Ainda assim, apesar da significativa participação de estudantes, muitas vezes de outros cursos, como serviço social, poucos manifestavam interesse em atuar efetivamente nos núcleos. Quando perguntados sobre as possíveis razões, obteve-se como resposta a questão do próprio perfil contra-hegemônico da prática em AJUP, além das dificuldades de deslocamento para muitos dos lugares em que se trabalhava e o pouco "lucro acadêmico" dessa prática extensionista, visto que o produtivismo não é um de seus objetivos, ainda que seja valorizada a sistematização das experiências.

Um aspecto relevante a destacar nesse ponto é quanto à diferença de conjuntura entre o período de surgimento das primeiras AJUPs no estado, em 2004 na UFPA Belém, e a atual realidade das universidades paraenses. O NAJUPAK e o NAJUP Isa Cunha foram os primeiros programas de extensão na história do curso de direito da UFPA; assim, os estudantes que possuíam interesse na pesquisa, na docência ou em desenvolver alguma prática diferenciada no direito, encontravam nesses núcleos uma possibilidade de atuação.

Com a expansão de projetos de pesquisa e extensão frutos, em grande parte, do período da “Política de Editais” dos anos de 2010, as AJUPs passaram a ser, com base na análise dos relatos, “marginalizadas”, a ter sua importância “secundarizada”. Esse processo se dá, provavelmente, por dois aspectos a serem destacados: o caráter diferenciado da atuação em AJUP, que, muitas vezes, não atende às expectativas de retorno meramente acadêmico, como horas complementares; e, principalmente, pelo contato declarado com causas e movimentos populares que vai contra o modelo hegemônico da formação jurídica presente nas universidades.

Com vista a confrontar essa realidade, alguns núcleos lograram reconhecimentos institucionais de sua prática, como o NAJUP-UFOPA, que conseguiu inserir a prática em extensão como parte da carga horária da prática jurídica exigida pelo curso, demonstrando a possibilidade de formular estratégias que favoreçam a prática em extensão popular. 
Ademais, em grande parte, as(os) estudantes que atuam em AJUP estão em contato direto com defensoras e defensores de direitos humanos (DDHs) e as violações de direitos que afetam os sujeitos e os grupos com os quais se trabalha, o que, desde então, permite às(aos) estudantes ter dimensão da realidade das violações enfrentadas por DDHs e a formulação de ferramentas que possam auxiliar no combate a essas violações. A formação de um estudante em AJUP está fortemente voltada para o campo da educação, sem, porém, eximir-se do direito como uma ferramenta de combate aos processos de criminalização e demais formas de violações de direitos, apontando para a necessidade de pôr em prática a especialidade da formação no campo jurídico (ALMEIDA, 2015).

Nas entrevistas, foi identificada a atuação em diversas atividades profissionais: advocacia e assessoria popular, assessoria no Ministério Público, docência e uma grande incidência de pessoas que continuaram desenvolvendo pesquisas na academia, seja como atividade principal ou paralelamente a outras atividades, além de haver dois estudantes envolvidos com a construção do NAJUP em Santarém e uma estudante de Belém em período de conclusão do curso.

As(os) entrevistadas(os) que já atuam profissionalmente perceberam a AJUP não só como contribuinte na escolha do caminho profissional tomado, mas como determinante. Mesmo aqueles que não tiveram o primeiro contato com as causas populares por meio das AJUPs atribuíram à sua experiência um importante papel na definição da perspectiva crítica de atuação pelo direito, sem perder de vista o pilar da educação popular com vista a seu caráter emancipatório. As(os) estudantes que estão na graduação manifestaram a expectativa de continuar atuando em defesa de DH, tendo sido diretamente influenciados pela experiência em AJUP, ainda que, também, houvessem tido experiências anteriores com discussões sobre direito crítico e com lutas de defensores de direitos humanos.

Percebeu-se que os núcleos que não tiveram relações fortalecidas com outros movimentos e/ou outras AJUPs enfrentaram muitas dificuldades para a atuação extensionista, a exemplo do NAJUP Cabano, que não teve oportunidade de trabalhar efetivamente para além da Universidade, sendo a ausência de contato com outros núcleos um dos fatores de dificuldades para execução das atividades.

A atuação da AJUP não é, portanto, um fim em si mesma, mas pode ser um ponto de partida para o processo de reconhecimento, formação e fortalecimento de estudantes que se forjam como defensores de direitos humanos, sendo determinante para a formação de profissionais que, posteriormente, desafiam-se nas ferramentas de luta em defesa de direitos humanos.

Uma das dificuldades indicadas para a continuidade de algumas AJUPs foi justamente a falta de perspectivas concretas de atuação para após a conclusão do curso de graduação. Elementos como 
a falta de perspectiva de sustento e instabilidade financeira e o próprio perigo de atuar como DDHs após a faculdade foram identificados como empecilhos na atuação profissional posterior, o que estimulou o afastamento de muitos integrantes dos núcleos.

Hoje, algumas importantes ONGs de defesa de direitos humanos no estado que trabalham com foco tanto nos conflitos agrários, como a Terra de Direitos, quanto no tema de segurança pública e violência urbana, como a SDDH, contam com o trabalho de pessoas que se formaram no seio da AJUP e carregam toda a bagagem dessa experiência na atuação profissional. É possível notar um diferencial entre aqueles profissionais que passam a atuar com a pauta de direitos humanos após a graduação e aqueles que iniciam a experiência ainda no curso. Dessa forma, a AJUP é uma possibilidade, dentro da rigidez do direito, de reorientação de sua prática, estando vinculada, porém, aos limites e contradições que permeiam a proposta de prática emancipadora utilizando-se de mecanismos formais. Assim, o contexto mais amplo de atuação e a influência da conjuntura política afetam diretamente a realidade dos núcleos.

De forma sintética, as dificuldades encontradas pelas AJUPs na efetividade de seu trabalho foram bastante semelhantes, apesar das especificidades de conjuntura de cada local e de cada grupo de pessoas que estava articulado na formação dos núcleos. Tal realidade, porém, foi resultado de uma série de fatores e especificidades que a própria região Norte enfrenta nessa forma de atuação. Com destaque, podem-se anotar algumas reflexões sobre as experiências de AJUPs no estado:

1) a AJUP no Pará foi uma das primeiras experiências em extensão universitária nas universidades e enfrentou, portanto, as dificuldades inerentes a qualquer terreno inexplorado e, também, a ausência de apoio institucional nesse sentido;

2) apesar de a vinculação institucional à universidade não ser determinante para a prática em AJUP, a possibilidade de apoio das instituições de ensino contribui para a execução das atividades de diversas formas, tanto pelo fornecimento de uma estrutura básica para a atuação, como pela possibilidade de inserção e alcance da proposta a outros estudantes, mas há a real dificuldade de adaptação da AJUP aos parâmetros burocráticos estabelecidos para esse acesso;

3) com a expansão da pesquisa e extensão nas universidades, a "concorrência” com outras formas de projeto que possibilitam maior "lucro acadêmico” afastam tanto estudantes como docentes da proposta de AJUP e dificultam o enraizamento do seu trabalho nas universidades e a aproximação de novas pessoas;

4) os parâmetros de atuação em AJUP, no sentido de criticidade à perspectiva de ensino jurídico, encontra resistência nos cursos, em especial pela lógica mercadológica e individualista que a universidade ainda sustenta; 
5) a inserção da AJUP na universidade, apesar da maior abertura e possibilidades de financiamento em comparação ao início, ainda é um desafio ao passo que a própria estrutura burocrática da universidade dificulta o reconhecimento dessa forma de atuação, seja pelo monopólio exclusivo de professores poderem propor projetos de extensão, seja pela sobrecarga causada pelo viés do ensino, que ainda é especialmente voltado para um caráter mercadológico, que dificulta a atuação extensionista;

6) Inexiste um corpo docente com experiência ou, minimamente, com abertura para essa forma de extensão e que seja capaz de compreender as proposições da AJUP;

7) a extensão territorial do estado e as especificidades da região amazônica imprimem diversas dificuldades de atuação em causas urgentes, como a reivindicação de grupos que se situam no ambiente rural, visto que as AJUPs atuantes no Pará se situavam em universidades localizadas em ambientes urbanos.

É preciso notar que, apesar do elemento “universidade” presente nessa prática, a AJUP pode atuar de forma ativa na construção de um projeto mais amplo de transformação da sociedade ao passo que disputa o discurso sobre a construção e ensino do direito nas universidades e se desafia na prática jurídica para além dela, propondo-se a romper com os parâmetros de prática jurídica hegemônica; além disso, como demonstrado, também é uma importante ferramenta de formação de profissionais que estão comprometidos com o combate de violação de direitos humanos na localidade onde atuam.

A AJUP se mostra como uma alternativa de atuação e disputa tanto dentro do próprio curso de direito, como para além dele, mas a proporção de alcance de efetividade de sua atuação dependerá de alguns fatores avaliados no desfecho do presente trabalho.

\section{CONCLUSÕES}

A AJUP é uma importante ferramenta de disputa no campo do direito, mostrando-se como uma proposta inovadora, apesar de ser uma prática que remonta os anos de 1950. Ela tem a importante tarefa de disputar uma perspectiva do direito associada à realidade de grupos vulnerabilizados a fim de transformá-lo numa proposta de atuação que rompa com a hierarquia forjada entre universidade e sociedade e entre profissionais do direito e os grupos com os quais se atua. O sustento no princípio da educação popular fornece a essa prática a possibilidade de formar profissionais de forma crítica e 
capazes de dialogar de forma diferenciada em relação aos demais profissionais que se formam nos moldes tradicionais impostos pelos cursos jurídicos.

O perfil da universidade no Brasil, em geral, ainda é representado por uma minoria privilegiada da sociedade, que tem a possibilidade de ingressar e permanecer nesse espaço. A partir da experiência de extensão popular protagonizada por estudantes, o contato com as mais diversas realidades permite não só uma formação diferenciada voltada para o uso da técnica jurídica, mas também para a perspectiva do uso do direito como ferramenta de emancipação.

Nesse aspecto, é fundamental salientar que as(os) estudantes que se forjam em AJUPs não são, nem serão, protagonistas das lutas sociais com as quais resolverem atuar, mas agentes de fomento das articulações necessárias para o fortalecimento das redes de defesa de direitos humanos. Pelas experiências concretas de AJUPs no estado do Pará, especialmente pela análise das mais antigas, foi possível avaliar que, de fato, essas vivências obtiveram resultados relevantes para o momento, apesar de bastante tímidos quando sob a ótica da proposta da AJUP. Por outro lado, pelas dificuldades identificadas, principalmente a partir do levantamento feito por meio das entrevistas, faz-se necessário buscar estratégias de atuação na atual conjuntura que sejam capazes de superar ou, ao menos, neutralizar as dificuldades históricas dessa atuação.

Não se pretende, aqui, elaborar determinações sobre a melhor ou pior forma de se atuar em AJUP, visto que essa prática pode ser muito diversa. Ainda assim, com a proposta de contribuir na (re)articulação de AJUPs no Pará, elaboraram-se algumas reflexões a partir das dificuldades encontradas pelas experiências precedentes:

1) há a necessidade de pensar a AJUP relacionada a um projeto de sociedade e de forma estratégica. A própria proposta de “extensão popular” trazida pela AJUP vislumbra a construção de uma universidade popular, como traçado no primeiro capítulo, inclusive por articulações que ultrapassem os limites da universidade, devendo ser pensada como o início da formação de profissionais que sejam capazes de atuar posteriormente em outros espaços;

2) deve-se determinar de forma objetiva as estratégias de formação e atuação da AJUP, mediante a formulação de um projeto político diferente daquele possivelmente apresentado para vinculação à universidade. Com essa ferramenta, seria possível delinear os elementos fundamentais de cada AJUP e propor uma meta de atuação em médio e longo prazo;

3) deve-se definir de forma objetiva as atividades desenvolvidas em cada período, buscandose executá-las prioritariamente, o que não exime de adaptá-las e alterá-las de acordo com as necessidades do grupo e da conjuntura, mas atendo-se às limitações da AJUP quanto à real capacidade de cumprimento dos objetivos; 
4) deve-se direcionar a AJUP para a atuação primordial que a educação popular delineia: a ruptura da opressão contra o oprimido. Dessa forma, apesar de se mostrar como uma estratégia diferenciada de inserção na universidade, a AJUP não pode perder o horizonte de atuação, em prol das classes populares de forma emancipadora e combatendo ferramentas de violação de direitos humanos, tanto dentro como fora da universidade;

5) devem ser buscadas formas de financiamento exteriores à universidade, não se rendendo ao assistencialismo e ao cumprimento de calendário de projetos, mas entendendo-os como ferramentas estratégicas que podem viabilizar financeiramente as atividades;

6) as AJUPs devem se articular com o corpo docente e, na medida do possível, obter acompanhamento que possa proporcionar um equilíbrio entre protagonismo e autonomia estudantil e atuação docente, além, como dito, de formar docentes que sejam capazes de entender e atuar posteriormente com a proposta;

7) deve-se manter uma rede de diálogo permanente com movimentos sociais e demais AJUPs atuantes no estado e no país;

8) devem ser registradas as atividades e deliberações e produzidas memórias a partir das vivências dos núcleos, visto que o registro documental é uma grande ferramenta de transferência de informações, inclusive ante a grande rotatividade de pessoas nas AJUPs;

9) deve-se manter a mística ou tesão, a fim de criar e fortalecer a identidade ajupiana;

10) devem ser difundidas as atividades executadas, por meios de divulgação eletrônicos e físicos;

11) deve-se manter a consciência de que o estudante ajupiano é apenas uma ferramenta atuante na rede de proteção, e que os protagonistas das mais diversas lutas são os próprios sujeitos;

12) devem ser cultivados os princípios de AJUP a partir do fazer-se coletivo, não se isentando da (auto)crítica necessária para combater os vícios inerentes aos trabalhos coletivos.

De forma sintética, a articulação em AJUP deve caminhar de forma articulada pela organização, formação, criação de identidade, trabalho de base, registro/produção e comunicação. Dessa forma, a AJUP se molda para além de um projeto de extensão acadêmica, aproximando-a da luta de movimentos populares, podendo atuar a partir:

1) da abertura dos mecanismos de acesso à justiça - judiciais ou extrajudiciais - para as comunidades com as quais atua;

2) da possibilidade de contribuir na (re)articulação de grupos de defesa de direitos humanos e comunidades, por meio da metodologia de educação popular; 
3) da inserção de debates, nas universidades, sobre temas relativos às causas estruturantes que sustentam os mecanismos de violação de direitos, como reforma agrária, reforma urbana e direito de comunidades e povos tradicionais;

4) da resistência ao tradicionalismo do direito e politização das demandas;

5) da formação de profissionais capazes de atuar não só de forma pontual, mas que tenham uma formação jurídica voltada à realidade de grupos vulnerabilizados e possam contribuir na sua articulação coletiva.

Por óbvio, o caminho de construção de AJUP não é fácil, da mesma forma que as diversas organizações populares enfrentam há décadas os desafios de resistir ante a realidade do Brasil, mas é preferível criar bases sólidas de atuação que sustentem um projeto maior de sociedade, do que optar pelo imediatismo e desvirtuar a ferramenta real de transformação que a AJUP pode ser. A AJUP, nesse cenário, pode atuar desde o embate na vivência universitária, até a formação de profissionais que atuam em defesa de direitos humanos.

\section{REFERÊNCIAS}

ALMEIDA, Ana Lia Vanderlei. A Atuação dos Grupos de Assessoria Jurídica Popular Universitária junto às Organizações Populares. In: OLIVEIRA, Assis da Costa; SANTOS, Julyanne Cristine Barbosa de Macedo; MOURA, Ana Paula Medeiros de (org.). Do sonho ao acontecer: 10 anos de NAJUPAK. V. 1. Belém: PROEX-UFPA, 2014. p. 12-29.

ALMEIDA, Ana Lia Vanderlei. Um estalo nas faculdades de Direito: perspectivas ideológicas da Assessoria Jurídica Universitária Popular. 2015. 340 f. Tese (Doutorado em Direito) - Programa de Pós-Graduação em Ciências Jurídicas, Universidade Federal da Paraíba, João Pessoa, 2015.

BARROS, Neibson Danilo Ferreira; SOUZA, Anne Mayre Lopes Jardim. Advocacia popular nos acampamentos Helenira Resende e Dalcidio Jurandir. In: XIII JORNADA DE EXTENSÃO UNIVERSITÁRIA, 2010, Belém. Anais [...]. Belém: PROEX, 2010.

BERNARDO, Caroline Costa; SANTOS, Julyanne Cristine Barbosa de Macedo; SANTOS, Sanmarie Rigaud dos. Projeto Juventude Cidadã: experiências a partir da educação popular em direitos humanos na Escola Francisco Nunes, Guamá/Belém. In: OLIVEIRA, Assis da Costa; SANTOS, Julyanne Cristine Barbosa de Macedo; MOURA, Ana Paula Medeiros de (org.). Do sonho ao acontecer: 10 anos de NAJUPAK. V. 1. Belém: PROEX-UFPA, 2014. p. 86-96.

BRASIL. Constituição da República Federativa do Brasil - 1988. Diário Oficial da União, Brasília, DF, 5 out. 1988. Disponível em: http://bit.ly/36g9gGM. Acesso em: 10 ago. 2016.

BRITTO JÚNIOR, Álvaro Francisco de; FERES JÚNIOR, Nazir. A Utilização da Técnica da Entrevista em Trabalhos Científicos. Evidência, Araxá, v. 7, n. 7, p. 237-250, 2011. 
CAMPILONGO, Celso Fernandes. Discutindo a Assessoria Popular. Rio de Janeiro: AJUP/FASE, 1991.

DIEHL, Diego Augusto. Universidade Popular. Captura Crítica: direito política e atualidade, Florianópolis, v. 2, n. 1, p. 423-435, jan./jun. 2009.

DUARTE, Madalena. Acesso ao direito e à justiça: Condições prévias de participação dos movimentos sociais na arena legal. Coimbra: Centro de Estudos Sociais, 2007. Disponível em: http://bit.ly/357fTuT. Acesso em: 10 ago. 2016.

ESCRIVÃO FILHO, Antônio Sérgio; SOUSA JUNIOR, José Geraldo de. Para um debate teóricoconceitual e político sobre os direitos humanos. Belo Horizonte: D’Plácido, 2016.

FREIRE, Paulo. Pedagogia da autonomia: saberes necessários à prática educativa. São Paulo: Paz e Terra, 2011.

FREIRE, Paulo. Pedagogia do oprimido: um reencontro com a pedagogia do oprimido. 54. ed. Rio de Janeiro: Paz e Terra, 2013.

GONDAR, Jô. A clínica como prática política. Lugar Comum, n. 19, p. 125-134, 2004.

INSTITUTO BRASILEIRO DE GEOGRAFIA E ESTATÍSTICA (IBGE). Síntese de Indicadores Sociais: uma análise das condições de vida da população brasileira - Tabelas 4.13 e 4.11. 2016. Disponível em: http://bit.ly/2P7Uyw1. Acesso em: 17 out. 2017.

LUZ, Vladimir de Carvalho. Assessoria Jurídica Popular no Brasil. Rio de Janeiro: Lumen Juris, 2007.

MATOS, Mariana Monteiro de. 4 anos de NAJUPAK: relato sobre as conversas de cozinha, a rotina ajupiana e a não exatidão da matéria. In: OLIVEIRA, Assis da Costa; SANTOS, Julyanne Cristine Barbosa de Macedo; MOURA, Ana Paula Medeiros de (org.). Do sonho ao acontecer: 10 anos de NAJUPAK. V. 1. Belém: PROEX-UFPA, 2014. p. 73-85.

MINISTÉRIO DA EDUCAÇÃO. Instituto Nacional de Estudos e Pesquisas Educacionais Anísio Teixeira (INEP). Censo da Educação Superior 2016. Notas Estatísticas. Disponível em: http://bit.ly/38maKRA. Acesso em: 17 out. 2017.

MONTEIRO, Aianny Naiara Gomes; MARTINS, Pedro Sérgio. O ensino jurídico e universidade popular: a experiência do Núcleo de Assessoria Jurídica Isa Cunha. Revista Direito \& Sensibilidade, Brasília, v. 1, n. 1, p. 251-266, 2011.

O ANEL de Tucum. Direção: Conrado Berning. Roteiro: Maria Inês Godinho; José W. Guimarães; Conrado Bening. Realização técnica e artística: Cinereu Kuhn. Trilha sonora: Sérgio Turcão. São Paulo: Verbo Filmes, 1994. 70 min, son. color. Disponível em: http://bit.ly/2RDqt91. Acesso em: 10 dez. 2017.

OLIVEIRA, Assis da Costa. Assessoria Jurídica Universitária Popular: bases comuns para rumos diferentes. Direito e Práxis, Rio de Janeiro, v. 1, n. 1, p. 110-126, 2010. 
OLIVEIRA, Assis da Costa; RAMOS, Ervelys Silva. Assessoria Interdisciplinar e Intercultural em Direitos Humanos: relato de experiência. Revista da Extensão, Porto Alegre, n. 4, p. 59-66, jul. 2012.

PAZELLO, Ricardo Prestes. Direito insurgente e movimentos populares: o giro descolonial do poder e a crítica marxista ao direito. 2014. 545 p. Tese (Doutorado em Direito) - Programa de PósGraduação em Direito, Universidade Federal do Paraná, Curitiba, 2014.

PEREIRA, Helayne Candido. Assessoria jurídica universitária popular - AJUP: Aportes históricos e teórico-metodológicos para uma nova práxis extensionista em direito. Revista Direito \& Sensibilidade, Brasília, v. 1, n. 1, p. 145-159, 2011.

PEREIRA, Sumaya Saady Morhy; OLIVEIRA, Assis da Costa. Rede Nacional das Assessorias Jurídicas universitárias: história, teoria e desafios. Revista da Faculdade de Direito da UFG, Goiânia, v. 33, n. 1, p. 152-166, jan./jun. 2009.

REDE NACIONAL DE ASSESSORIA JURÍDICA POPULAR (RENAJU). Estatuto do Tesão. Revista InSURgência, Brasília, v. 2, n. 2, p. 460-462, 2016.

RIBAS, Luiz Otávio. Assessoria jurídica popular universitária. Captura Críptica: direito, política e atualidade. Florianópolis, v. 1, n. 1, p. 246- 254, jul./dez. 2008.

RIBEIRO, Cristina Figueiredo Terezo. Rede Amazônica de Clínicas de Direitos Humanos. In: IX Encontro da Associação Nacional de Direitos Humanos, Pesquisa e Pós-Graduação, 2015, Anais [...]. Vitória: ANDHEP, 2016.

SAMPAIO OLIVEIRA, Murilo Carvalho. Serviço de Apoio Jurídico - SAJU: a práxis de um Direito Crítico. 2003. 74 f. Trabalho de Conclusão de Curso (Bacharelado em Direito) - Faculdade de Direito, Universidade Federal da Bahia, Salvador, 2003.

SANTOS, Boaventura de Sousa. Para uma Revolução Democrática da Justiça. 3. ed. São Paulo: Cortez, 2011.

SANTOS, Boaventura de Sousa. Pela mão de Alice: o social e o político na pós-modernidade. 10. ed. São Paulo: Cortez, 2005.

SANTOS, Julyanne Cristine Barbosa de Macedo; CAVALCANTE, Breno Neno Silva. NAJUP Aldeia Kayapó: 10 anos em defesa de direitos humanos. In: OLIVEIRA, Assis da Costa; SANTOS, Julyanne Cristine Barbosa de Macedo; MOURA, Ana Paula Medeiros de (org.). Do sonho ao acontecer: 10 anos de NAJUPAK. V. 1. Belém: PROEX-UFPA, 2014. p. 48-58.

WOLKMER, Antônio Carlos. Pluralismo Jurídico: Fundamentos de uma nova cultura do Direito. 3. ed. São Paulo: Alfa-Omega, 2001. 
Julyanne Cristine Barbosa de Macedo dos Santos Mestranda no Programa de Pós-Graduação em Direito da Universidade Federal do Pará. Email: macedo.july@hotmail.com

Paula Regina Benassuly Arruda

Pós-Doutora pela Universidade de Duisburg-Essen (Alemanha). Doutora em Direitos Humanos pela Universidade de Salamanca (Espanha). Professora na Universidade Federal do Pará, com ênfase em Direito Constitucional e Direitos Humanos. Coordenadora do Laboratório de Justiça Global e Educação em Direitos Humanos na Amazônia (Lajusa). Email: paularruda_pa@yahoo.com.br 